\title{
The Effect of Platelet Age on
}

\section{Platelet Adherence to Collagen}

\author{
J. Hirsh, M. F. Glynn, and J. F. Mustard \\ From the Blood and Vascular Disease Research Unit, Departments of \\ Medicine and Pathology, University of Toronto, Toronto, Ontario, \\ and the Department of Pathology, McMaster University, \\ Hamilton, Ontario
}

A в S T R A C T The adherence to collagen of rabbit platelets labeled in vivo with ${ }^{35} \mathrm{SO}_{4}{ }^{2}$ has been studied both in vitro and in vivo. The young platelets are labeled with ${ }^{35} \mathrm{SO}_{4}=2-3$ days after administration of the isotope to the animals. We exposed platelet-rich plasma (ethylenediaminetetraacetate, EDTA, as anticoagulant), prepared from blood taken from rabbits $54 \mathrm{hr}$ after giving the ${ }^{35} \mathrm{SO}_{4}{ }^{\prime}$, to collagen in vitro. There was a fall in the specific radioactivity of the nonadherent platelets which indicated a selective adhesion of young platelets to the collagen. In experiments designed to have most of the ${ }^{35} \mathrm{~S}$ label in the oldest platelets it was found that exposure of plasma containing these platelets to collagen resulted in an increase in the specific radioactivity of the nonadherent platelets. Similar observations were obtained when glycine- ${ }^{14} \mathrm{C}$ was used as a platelet label. However, when $\mathrm{DF}^{32} \mathrm{P}$ (di-isopropyl phosphorofluoridate ${ }^{32} \mathrm{P}$ ), which is thought to label platelets of all ages equally, was used, the adherence of platelets to collagen did not result in any changes in the specific activity of the nonadherent platelets. In in vivo studies in which we infused a collagen suspension into rabbits $54 \mathrm{hr}$ after giving ${ }^{35} \mathrm{SO}_{4}=$ we found that the specific radioactivity of the platelets remaining in the circulation fell. This did not occur when we infused

Dr. J. Hirsh was a visiting scientist of the Canadian Heart Foundation. His present address is University of Melbourne, Department of Medicine, St. Vincent's Hospital, Melbourne, Australia.

Received for publication 25 September 1967 and in revised form 6 November 1967. the collagen $96 \mathrm{hr}$ after giving the ${ }^{35} \mathrm{SO}_{4}=$. The results from these studies indicate that young platelets adhere to collagen more readily than older platelets.

\section{INTRODUCTION}

In 1942 Wright (1) observed that the postoperative and postpartum rise in platelet counts was paralleled by a rise in platelet adhesiveness. She suggested that the increased platelet adhesiveness might be the consequence of an increased concentration of young platelets in the circulation and that, therefore, young platelets might be more adhesive than old platelets.

It is possible to study in a semiquantitative manner, platelet adherence to collagen and other surfaces (2). The administration of ${ }^{35} \mathrm{SO}_{4}{ }^{=}$or glycine- ${ }^{14} \mathrm{C}$ to rats, pigs, or rabbits leads to the labeling of a cohort of young platelets on the 2 nd or 3rd day (3-5). $\mathrm{DF}^{32} \mathrm{P}$ (di-isopropyl phosphorofluoridate- $\left.{ }^{32} \mathrm{P}\right)$ is considered to label platelets of all ages $(6,7)$. If the younger platelets preferentially adhere to surfaces, then upon exposure to collagen, the specific activity of the nonadherent platelets should fall when the young platelets are labeled, whereas there should be no change in the specific activity when the whole population is labeled. We have used these considerations to study both in vivo and in vitro the relationship between platelet age and platelet adherence to collagen. In addition, we have examined whether the adherence of platelets to each other, induced by 
adenosine diphosphate (ADP), is also influenced by platelet age.

In order to assess platelet adherence to collagen in the absence of platelet aggregation we performed these studies with platelet-rich plasma (PRP) prepared from blood mixed with disodium ethylenediaminetetraacetate (EDTA). Platelets can adhere to surfaces in the presence of EDTA but not to each other (2). When studying ADP-induced adherence of platelets to each other, we used platelet-rich plasma prepared from blood taken into citrate.

\section{METHODS}

Radioisotopes. Radioactive inorganic sulfate $\left({ }^{85} \mathrm{~S}\right)$ in $\mathrm{HCl}$, (carrier free) was obtained from the Atomic Energy Commission of Canada, Chalk River, Ontario. $\mathrm{DF}^{\mathrm{s}} \mathrm{P}$, sterile solution in propylene glycol (DFP- ${ }^{\mathrm{s}} \mathrm{P}$ ) (specific activity at time of shipment $200-240 \mu \mathrm{c} / \mathrm{mg}$ of DFP), glycine- $\mathrm{U}^{-14} \mathrm{C}(8 \mathrm{mc} / \mathrm{mmole}$ and 5 - hydroxytryptamine- $3^{\prime}$ creatinine sulfate- ${ }^{14} \mathrm{C}$ (serotonin $-{ }^{14} \mathrm{C}, 10-35 \mathrm{mc} /$ mmole) were obtained from the Radiochemical Centre, Amersham, England.

Adenosine diphosphate. ADP (Sigma Chemical Co., St. Louis, Mo.) was dissolved in Tyrode's solution $(\mathrm{pH}$ 7.4) at the required concentration.

Collagen. Commercial collagen (Sigma Chemical Co.) was used as fibers or as a fine suspension prepared by the method of Hovig (8), from $2 \mathrm{~g}$ of commercial collagen in $100 \mathrm{ml}$ of Tyrode's solution.

Rabbits. The rabbits used were the white New Zealand breed and weighed between 3 and $4 \mathrm{~kg}$.

Blood samples. Blood for platelet counts and radioactivity determinations was withdrawn from anesthetized rabbits (intravenous sodium pentobarbital) through a silicone-coated plastic carotid cannula into a disposable plastic syringe. The blood was rapidly mixed with either $3.8 \%$ trisodium citrate or 2\% EDTA (2\% disodium ethylenediaminetetraacetate, $0.33 \% \quad \mathrm{NaCl}) \quad(9$ parts of blood to one part of anticoagulant) in a silicone-coated glass centrifuge tube. PRP was prepared by centrifugation at $77 \mathrm{~g}$ for $15 \mathrm{~min}$.

Platelet suspensions. The preparation of washed platelets in suspension in Tyrode's gelatin solution has been described previously (9).

Platelet labeling with radioactive sulfur $\left({ }^{35} \mathrm{SO}_{4}=\right), 200$ $\mu \mathrm{c}$ of ${ }^{{ }^{8}} \mathrm{SO}_{4}=$ was administered by intravenous injection. Blood was withdrawn at $54 \mathrm{hr}$ or $96 \mathrm{hr}$ after the injection. In some instances the blood was obtained from one animal at different times for test purposes. However, in most cases a different animal was used for each study. From Fig. 1 it can be seen that there was a sharp rise in circulating ${ }^{25} \mathrm{~S}$-labeled platelets about $40-44 \mathrm{hr}$ after administration of the isotope. This reached a peak between 50 and $72 \mathrm{hr}$ and then fell off sharply. Thus, labeled platelets recovered $54 \mathrm{hr}$ after administration of the isotope would be predominantly a cohort of young platelets, and those recovered $96 \mathrm{hr}$ after isotope administration would be predominantly old platelets.

Platelet labeling with glycine $-{ }^{14} C$. Blood was withdrawn $54 \mathrm{hr}$ after administration of $10 \mu \mathrm{c}$ of glycine $-{ }^{14} \mathrm{C}$ in the same manner as in the ${ }^{25} \mathrm{~S}$ experiments. This isotope had a similar pattern of incorporation into the platelets and the labeled platelets in the samples taken at $54 \mathrm{hr}$ represent a cohort of young platelets.

Platelet labeling with $D F^{s s} P$. Blood was withdrawn $6 \mathrm{hr}$ after the administration of $30 \mu \mathrm{c}$ of $\mathrm{DF}^{\mathrm{s}} \mathrm{P}$ by intravenous infusion. This labeled compound labels all circulating platelets as well as other formed elements and the proteins in the blood.

${ }^{35} \mathrm{~S}$ as an old platelet population label. ${ }^{85} \mathrm{SO}_{4}=$ was administered intravenously to rabbits in a dosage of 200 $\mu \mathrm{c}$ on the $1 \mathrm{st}$ day and then $70 \mu \mathrm{c}$ each day for 7 days. Blood was withdrawn $72 \mathrm{hr}$ after the last injection. With this method of administration, the platelet radioactivity gradually rose and reached a plateau at about 5-6 days, at which time it was assumed that platelets of all ages

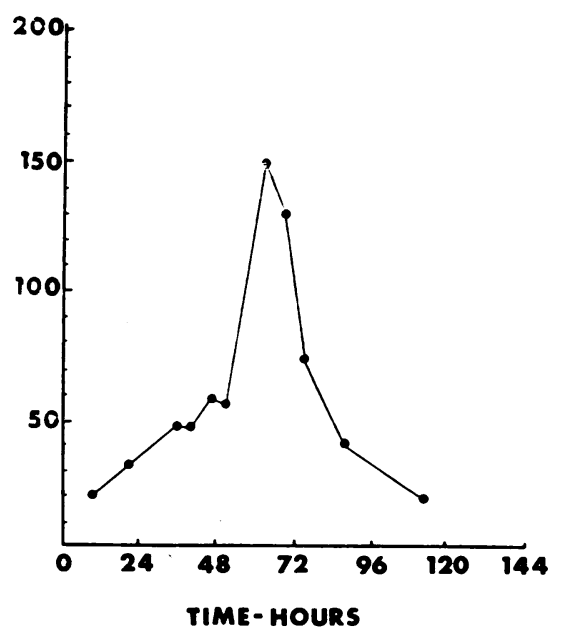

FIGURE 1 This shows the radioactivity of platelets isolated from the blood of a rabbit at intervals after the intravenous injection of ${ }^{35} \mathrm{SO}_{4}=$ The platelets were washed three times, and then their radioactivity was measured and expressed as counts per minute per milligram platelets on the ordinate. 
were equally labeled. By taking blood $72 \mathrm{hr}$ later, one is theoretically able to obtain a population of platelets in which the older platelets are much more heavily labeled than the young platelets.

Measurement of platelet adhesiveness to collagen. These studies were carried out with a method which has been described by Hovig, J фrgensen, Packham, and Mustard (2). EDTA platelet-rich plasma was exposed for $20 \mathrm{~min}$ at $37^{\circ} \mathrm{C}$ in a turbidimetric device to $0.1 \mathrm{~g}$ of wet collagen fibers wrapped around a metal stirring bar (10). The covered bar was stirred magnetically at a constant rate of $1100 \mathrm{rpm}$. The progressive adhesion of platelets to the collagen produced a steady fall in optical density which was accompanied by a characteristic deflection of the recorder pen. After $20 \mathrm{~min}$ the collagen and stirring bar were removed. We recovered platelets remaining in the plasma and washed them three times in Tyrode'salbumin-EDTA solution using methods which have been described (9). A similar washed platelet suspension was prepared from a sample of platelet-rich plasma not exposed to the collagen.

The number of platelets in the platelet suspension was determined with a Coulter counter by a method which has been previously described (11). In addition, $0.1 \mathrm{ml}$ of the platelet suspension was placed in Hyamine and added to a toluene-fluor solution (2,5-diphenyloxazole, 1,4-bis [2-(5-phenyloxazoly1)] benzene) containing ethanol for determination of the radioactivity. The radioactivity was measured in a Nuclear-Chicago liquid scintillation counter (11). The specific radioactivity was expressed as counts per minute per $10^{6}$ or $10^{\circ}$ platelets.

Platelet counts were also done on the platelet-rich plasma before and after exposure to collagen. The fall in platelet count and the gradual increase in light transmission over the period of $20 \mathrm{~min}$ was primarily a reflection of platelet adhesion to the collagen. Phase contrast microscopy showed that the platelets were adherent to the collagen but were not present in clumps. The collagen was removed from the stirring bar, washed three times in Tyrode's solution, and placed in Hyamine. The toluene-flour solution was added for liquid scintillation counting.

Platelet aggregation with $A D P$. The blood used in these experiments was obtained from rabbits given ${ }^{35} \mathrm{SO}_{4}=$ $54 \mathrm{hr}$ earlier.

ADP, $0.3 \mu \mathrm{g}$ (0.62 nanomoles) in $0.1 \mathrm{ml}$ of Tyrode's solution, was added to $0.9 \mathrm{ml}$ of citrated platelet-rich plasma in a cuvette and the mixture stirred magnetically in a turbidimetric device as described previously (10). This concentration of ADP did not aggregate all the platelets. When the fall in optical density had reached a maximum the tube was placed in an ice bath. The platelet-rich plasmas from reacted and nonreacted samples were then centrifuged at $4^{\circ} \mathrm{C}$ at $100 \mathrm{~g}$ for $10 \mathrm{~min}$ in order to sediment aggregated platelets. The platelets remaining in the supernatant from both the ADP treated PRP and the control PRP were separated and washed three times in Tyrode's-albumin-EDTA. Platelet counts and radioactivity were determined as in the collagen experiments.
In vivo infusion of collagen. Over a period of $3 \mathrm{~min}$, $20 \mathrm{ml}$ of the collagen suspension was infused into the femoral artery of anesthetized rabbits which had received ${ }^{35} \mathrm{SO}_{4}=$ either 54 or $96 \mathrm{hr}$ previously. Blood was withdrawn through a cannula in the carotid artery before injection, $1 \mathrm{~min}$ after injection, and $60 \mathrm{~min}$ after injection, for determinations of the number of platelets per $\mathrm{mm}^{3}$ and of platelet specific radioactivity.

In vivo infusions of $A D P$. Over a period of $5 \mathrm{~min}$, ADP, 300 milligrams ( 0.62 millimoles) in $10 \mathrm{ml}$ of $\mathrm{Ty}-$ rode's solution $\mathrm{pH} 7.4$, was infused into a femoral artery of an anesthetized rabbit which had received ${ }^{35} \mathrm{SO}_{4}=54 \mathrm{hr}$ previously. Blood was withdrawn through a carotid cannula before the ADP infusion and at the following intervals after infusion: 1,10 , and $90 \mathrm{~min}$.

TABLE I

Platelet Radioactivity and Platelet Count before and after Exposure of ${ }^{35}$ S-Labeled Platelets to Collagen Fibers in EDTA Platelet-Rich Plasma

\begin{tabular}{|c|c|c|c|c|}
\hline \multirow[b]{2}{*}{ Experiment } & \multicolumn{2}{|c|}{ Platelet radioactivity } & \multicolumn{2}{|c|}{ Platelet count } \\
\hline & $\begin{array}{c}\text { Before } \\
\text { collagen }\end{array}$ & $\begin{array}{c}\text { After } \\
\text { collagen }\end{array}$ & $\begin{array}{l}\text { Before } \\
\text { collagen }\end{array}$ & $\begin{array}{c}\text { After } \\
\text { collagen }\end{array}$ \\
\hline & $c p m / 10^{6}$ & platelets & No./mn & $n^{3} \times 10^{8}$ \\
\hline
\end{tabular}

54 hrs after ${ }^{35} \mathrm{SO}_{4}-$ injection

$\begin{array}{rrrrr}1 & 98 & 30 & 240 & 209 \\ 2 & 111 & 74 & 266 & 214 \\ 3 & 114 & 111 & 270 & 284 \\ 4 & 74 & 37 & 348 & 314 \\ 5 & 190 & 100 & 290 & 210 \\ 6 & 188 & 134 & 300 & 285 \\ 7 & 107 & 44 & 320 & 210 \\ 8 & 348 & 340 & 261 & 241 \\ 9 & 238 & 139 & 304 & 264 \\ 10 & 269 & 218 & 265 & 260\end{array}$

Significance of

differences

between values

before and

$\mathrm{t}=5.19$

$\mathrm{t}=3.25$

after exposure

$P<0.001 \quad P<0.01$

to collagen

$96 \mathrm{hr}$ after ${ }^{35} \mathrm{SO}_{4}-$ injection

$\begin{array}{rrrrr}1 & 21 & 39 & 176 & 145 \\ 2 & 45 & 44 & 432 & 360 \\ 3 & 101 & 100 & 290 & 250 \\ 4 & 16 & 16 & 276 & 280 \\ 5 & 36 & 37 & 258 & 230 \\ 6 & 443 & 375 & 397 & 340\end{array}$

Significance of differences between values

before and after exposure to collagen 
TABLE II

Distribution of Radioactivity before and after EDTA-PRP* Containing ${ }^{35} S$-Labeled Platelets Was Exposed to Collagen Fibers

\begin{tabular}{|c|c|c|c|c|c|}
\hline \multirow[b]{2}{*}{$\begin{array}{l}\text { Experi- } \\
\text { ment }\end{array}$} & \multicolumn{2}{|c|}{ Platelets } & \multicolumn{2}{|c|}{ Platelet-free plasma } & \multirow[b]{2}{*}{$\begin{array}{l}\text { Collagen } \\
\text { fragmen }\end{array}$} \\
\hline & $\begin{array}{c}\text { Before } \\
\text { collagen }\end{array}$ & $\begin{array}{c}\text { After } \\
\text { collagen }\end{array}$ & $\begin{array}{c}\text { Before } \\
\text { collagen }\end{array}$ & $\begin{array}{c}\text { After } \\
\text { collagen }\end{array}$ & \\
\hline & \multicolumn{2}{|c|}{ cpm $/ 10^{\circ}$ platelets } & \multicolumn{2}{|c|}{$c p m / m l$} & $c p m$ \\
\hline 1 & 1730 & 1315 & 5359 & 4302 & 489 \\
\hline 2 & 986 & 432 & 591 & 559 & 195 \\
\hline 3 & 2235 & 1428 & 11,225 & 11,615 & 387 \\
\hline
\end{tabular}

* Prepared from rabbit blood taken $54 \mathrm{hr}$ after injection of ${ }^{35} \mathrm{SO}_{4}{ }^{2}$. In these experiments the animals were given $50 \mu \mathrm{c}$ of ${ }^{35} \mathrm{SO}_{4}{ }^{-}$instead of $200 \mu \mathrm{c}$.

\section{RESULTS}

Table I shows the results of experiments in which platelet-rich plasma was prepared from rabbits given ${ }^{35} \mathrm{SO}_{4}=54$ or $96 \mathrm{hr}$ previously. Exposure of EDTA platelet-rich plasma to collagen fragments decreased the radioactivity associated with platelets in samples from the $54 \mathrm{hr}$ period; since the fall was in the specific radioactivity of the platelets it represents a selective adhesion of young platelets to the collagen. This effect was not seen with samples prepared from blood drawn $96 \mathrm{hr}$ after the administration of the isotope. During the period in which the platelet-rich plasma was exposed to collagen there was evidence of progressive adhesion of the platelets to collagen, but no evidence of platelet aggregation. This was determined by the slow but steady increase in light transmission as the collagen was stirred in the platelet-rich plasma, the fall in the platelet count, and failure to detect platelet aggregates in the samples of EDTA platelet-rich plasma examined by phase contrast microscopy.

Since ${ }^{35} \mathrm{~S}$-labeled platelets are known to release ${ }^{35} \mathrm{~S}$-labeled material when exposed to thrombin, the possibility that collagen also might cause the release of ${ }^{35} \mathrm{~S}$-labeled material had to be considered. In Table II it can be seen that when platelets suspended in EDTA-PRP were exposed to collagen there was no evidence of an increase in radioactivity in the plasma. The radioactivity of the platelets before and after exposure to collagen and of the collagen fragments is also shown.

When collagen, to which ${ }^{35} \mathrm{~S}$-labeled platelets were adherent, was exposed to nonlabeled EDTA
TABLE III

Platelet Radioactivity and Platelet Count before and after Exposure of ${ }^{14} \mathrm{C}$-Labeled Glycine Platelets* to Collagen Fibers in EDTA-PRP

\begin{tabular}{|c|c|c|c|c|}
\hline \multirow[b]{2}{*}{ Experiment } & \multicolumn{2}{|c|}{ Platelet radioactivity } & \multicolumn{2}{|c|}{ Platelet count } \\
\hline & $\begin{array}{l}\text { Before } \\
\text { collagen }\end{array}$ & $\begin{array}{c}\text { After } \\
\text { collagen }\end{array}$ & $\begin{array}{c}\text { Before } \\
\text { collagen }\end{array}$ & $\begin{array}{c}\text { After } \\
\text { collagen }\end{array}$ \\
\hline & \multicolumn{2}{|c|}{$c p m / 10^{6}$ platelets } & \multicolumn{2}{|c|}{$\mathrm{No.} / \mathrm{mm}^{3} \times 10^{3}$} \\
\hline 1 & 180 & 130 & 250 & 225 \\
\hline 2 & 163 & 67 & 389 & 329 \\
\hline 3 & 234 & 200 & 280 & 260 \\
\hline 4 & 185 & 173 & 275 & 280 \\
\hline 5 & 204 & 123 & 268 & 235 \\
\hline 6 & 190 & 140 & 250 & 240 \\
\hline $\begin{array}{l}\text { Significance of } \\
\text { differences } \\
\text { between values }\end{array}$ & \multicolumn{2}{|c|}{$\mathrm{t}=4.41$} & \multicolumn{2}{|c|}{$t=2.62$} \\
\hline $\begin{array}{l}\text { before and } \\
\text { after exposure } \\
\text { to collagen }\end{array}$ & \multicolumn{2}{|c|}{$P<0.005$} & \multicolumn{2}{|c|}{$P<0.05$} \\
\hline
\end{tabular}

* Prepared from rabbit blood taken $54 \mathrm{hr}$ after injection of the glycine- ${ }^{-14} \mathrm{C}$.

platelet-rich plasma there was no detectable elution of radioactivity into the plasma.

Since these results with ${ }^{35} \mathrm{SO}_{4}=$ might have been due to an artefact associated with ${ }^{35}$ S-labeling, some of the experiments were repeated with glycine $-{ }^{14} \mathrm{C}$ as a cohort label. Platelets labeled with glycine- ${ }^{14} \mathrm{C}$ showed no loss of radioactivity into

TABLE IV

Adherence of $D F^{32} P$-Labeled Platelets to Collagen Fibers in EDTA-PRP

\begin{tabular}{|c|c|c|c|c|}
\hline \multirow[b]{2}{*}{ Experiment } & \multicolumn{2}{|c|}{ Platelet radioactivity } & \multicolumn{2}{|c|}{ Platelet count } \\
\hline & $\begin{array}{c}\text { Before } \\
\text { collagen }\end{array}$ & $\begin{array}{l}\text { After } \\
\text { collagen }\end{array}$ & $\begin{array}{l}\text { Before } \\
\text { collagen }\end{array}$ & $\begin{array}{l}\text { After } \\
\text { collagen }\end{array}$ \\
\hline & \multicolumn{2}{|c|}{$c p m / 10^{6}$ platelets } & \multicolumn{2}{|c|}{ No. $/ \mathrm{mm}^{3} \times 10^{\mathrm{s}}$} \\
\hline 1 & 77 & 78 & 260 & 212 \\
\hline 2 & 114 & 112 & 250 & 210 \\
\hline 3 & 118 & 119 & 281 & 250 \\
\hline 4 & 51 & 54 & 290 & 242 \\
\hline 5 & 93 & 91 & 162 & 111 \\
\hline 6 & 153 & 127 & 184 & 154 \\
\hline
\end{tabular}

Significance of differences between values before and $\begin{array}{ll}\mathrm{t}=0.925 & \mathrm{t}=10.7 \\ P>0.2 & P<0.005\end{array}$ after exposure to collagen 
the ambient fluid when exposed to collagen in EDTA platelet-rich plasma. It can be seen from Table III that when a population of platelets containing a young cohort of ${ }^{14} \mathrm{C}$-labeled platelets was exposed to collagen there was a selective removal of the radioactive platelets.

However, when $\mathrm{DF}^{32} \mathrm{P}$ [which is thought to label platelets of all ages (5)] was used, a different pattern emerged. It can be seen from Table IV that although there was a fall in the platelet count, there was no significant change in the specific radioactivity of these platelets before and after exposure to collagen.

In further studies, ${ }^{35} \mathrm{SO}_{4}{ }^{2}$ was given daily for $T$ days. Blood was withdrawn and mixed with EDTA $72 \mathrm{hr}$ after the last injection, and platelet-rich plasma was prepared and exposed to collagen. In these experiments it can be assumed that the label was predominantly in the oldest platelets. In contrast to the experiments in which young platelets were labeled (Table I), there was an increase in the specific radioactivity of the nonadherent platelets after exposure to collagen (Table V).

Table VI shows the results of experiments in which a population of platelets containing a young cohort of ${ }^{\mathbf{3 5}} \mathrm{S}$-labeled platelets in citrated platelet-

\section{TABLE $V$}

Platelet Radioactivity and Platelet Count before and after Exposure to Collagen Fibers of a Population of Platelets Containing ${ }^{35} S$-Labeled Old Platelets in EDTA-PRP

\begin{tabular}{|c|c|c|c|c|}
\hline \multirow[b]{2}{*}{ Experiment } & \multicolumn{2}{|c|}{ Platelet radioactivity } & \multicolumn{2}{|c|}{ Platelet count } \\
\hline & $\begin{array}{l}\text { Before } \\
\text { collagen }\end{array}$ & $\begin{array}{c}\text { After } \\
\text { collagen }\end{array}$ & $\begin{array}{c}\text { Before } \\
\text { collagen }\end{array}$ & $\begin{array}{c}\text { After } \\
\text { collagen }\end{array}$ \\
\hline & \multicolumn{2}{|c|}{ cpm $/ 10^{6}$ platelets } & \multicolumn{2}{|c|}{ No. $/ \mathrm{mm}^{3} \times 10^{3}$} \\
\hline 1 & 42 & 83 & 276 & 204 \\
\hline 2 & 70 & 72 & 284 & 264 \\
\hline 3 & 69 & 72 & & \\
\hline 4 & 218 & 229 & 290 & 215 \\
\hline 5 & 445 & 531 & 225 & 189 \\
\hline 6 & 600 & 630 & 223 & 178 \\
\hline 7 & 104 & 111 & 250 & 224 \\
\hline 8 & 99 & 110 & 260 & 240 \\
\hline 9 & 102 & 112 & 190 & 160 \\
\hline $\begin{array}{l}\text { Significance of } \\
\text { differences } \\
\text { between values }\end{array}$ & \multicolumn{2}{|c|}{$\mathrm{t}=2.44$} & \multicolumn{2}{|c|}{$\mathrm{t}=5.57$} \\
\hline $\begin{array}{l}\text { before and } \\
\text { after exposure } \\
\text { to collagen }\end{array}$ & \multicolumn{2}{|c|}{$P<0.05$} & \multicolumn{2}{|c|}{$P<0.005$} \\
\hline
\end{tabular}

TABLE VI

Radioactivity of ${ }^{35} \mathrm{~S}$-Labeled Platelets (54 Hr after Isotope Injection) before and after Exposure to $A D P$ in Citrated PRP

\begin{tabular}{|c|c|c|}
\hline \multirow[b]{2}{*}{ Experiment } & \multicolumn{2}{|c|}{$\begin{array}{l}\text { Radioactivity of non- } \\
\text { aggregated platelets }\end{array}$} \\
\hline & Before ADF & After ADP \\
\hline & \multicolumn{2}{|c|}{$\mathrm{cpm} / 10^{6}$ platelets } \\
\hline 1 & 330 & 395 \\
\hline 2 & 259 & 390 \\
\hline 3 & 300 & 324 \\
\hline 4 & 288 & 316 \\
\hline 5 & 183 & 136 \\
\hline 6 & 117 & 60 \\
\hline 7 & 428 & 645 \\
\hline $\begin{array}{l}\text { Significance of differences } \\
\text { between values before } \\
\text { and after ADP }\end{array}$ & \multicolumn{2}{|c|}{$\begin{aligned} \mathrm{t} & =1.41 \\
P & >0.1\end{aligned}$} \\
\hline
\end{tabular}

rich plasma was exposed to ADP. It can be seen that there was no significant difference in the specific radioactivity of the platelets before exposure to ADP and those left in the supernatant after the aggregated platelets had been removed by centrifugation.

In vivo experiments. It can be seen from $\mathrm{Ta}-$ ble VII that infusion of collagen into rabbits injected $54 \mathrm{hr}$ previously with ${ }^{35} \mathrm{SO}_{4}=$ produced a moderate fall in the platelet count at $60 \mathrm{~min}$ but a marked fall in the radioactivity associated with the platelets. However, when the collagen was infused into rabbits injected with ${ }^{35} \mathrm{SO}_{4}=96 \mathrm{hr}$ previously there was no decrease in the radioactivity associated with the platelets and in four experiments there was an increase.

The infusion of ADP into rabbits injected 54 hr previously with ${ }^{35} \mathrm{SO}_{4}=$ produced a transient fall in the platelet count but there was no fall in the radioactivity associated with the platelets (Table VIII).

\section{DISCUSSION}

Odell, Tausche, and Gude (3) showed that when ${ }^{35} \mathrm{SO}_{4}=$ was injected into rats the radioisotope was incorporated into megakaryocytes in the bone marrow. Radioautography revealed that the radioactivity of these cells reached a peak at about the 2nd day. This was followed by a large increase in the platelet radioactivity. A similar pattern of label- 
TABLE VII

Platelet Radioactivity and Platelet Count before and after Infusion of Collagen Suspension

\begin{tabular}{|c|c|c|c|c|c|}
\hline \multirow[b]{2}{*}{ Experiment } & \multicolumn{2}{|c|}{ Platelet radioactivity } & \multicolumn{3}{|c|}{ Platelet count } \\
\hline & $\begin{array}{l}\text { Before } \\
\text { collagen } \\
\text { infusion }\end{array}$ & $\begin{array}{l}60 \text { min after } \\
\text { collagen } \\
\text { infusion }\end{array}$ & $\begin{array}{l}\text { Before } \\
\text { collagen } \\
\text { infusion }\end{array}$ & $\begin{array}{l}1 \text { min after } \\
\text { collagen } \\
\text { infusion }\end{array}$ & $\begin{array}{l}60 \text { min after } \\
\text { collagen } \\
\text { infusion }\end{array}$ \\
\hline & \multicolumn{2}{|c|}{$c p m / 10^{6}$ platelets } & \multicolumn{3}{|c|}{$\mathrm{No} . / \mathrm{mm}^{2} \times 10^{3}$} \\
\hline \multicolumn{6}{|l|}{ Collagen infused $54 \mathrm{hr}$ after ${ }^{35} \mathrm{SO}_{4}-$ administration } \\
\hline 1 & 663 & 225 & 262 & 72 & 210 \\
\hline 2 & 345 & 193 & 282 & 41 & 214 \\
\hline 3 & 238 & 77 & 294 & 104 & 215 \\
\hline 4 & 269 & 77 & 257 & 65 & 193 \\
\hline 5 & 118 & 75 & 600 & 250 & 400 \\
\hline 6 & 270 & 126 & 750 & 300 & 400 \\
\hline Significance of differences between values & \multicolumn{2}{|c|}{$\mathrm{t}=3.48$} & \multicolumn{3}{|c|}{$\mathrm{t}=2.59$} \\
\hline before and $60 \mathrm{~min}$ after infusion: & \multicolumn{2}{|c|}{$P<0.02$} & \multicolumn{3}{|c|}{$P<0.05$} \\
\hline \multicolumn{6}{|l|}{ Collagen infused $96 \mathrm{hr}$ after ${ }^{35} \mathrm{SO}_{4}^{-}$administration } \\
\hline 1 & 237 & 240 & 408 & 298 & 366 \\
\hline 2 & 420 & 400 & 367 & 180 & 300 \\
\hline 3 & 68 & 102 & 450 & 320 & 400 \\
\hline 4 & 96 & 123 & 850 & 275 & 680 \\
\hline 5 & 95 & 104 & 900 & 710 & 820 \\
\hline Significance of differences between values & \multicolumn{2}{|c|}{$\mathrm{t}=1.11$} & \multicolumn{3}{|c|}{$t=3.48$} \\
\hline before and $60 \mathrm{~min}$ after infusion & \multicolumn{2}{|c|}{$P<0.4$} & \multicolumn{3}{|c|}{$P<0.02$} \\
\hline
\end{tabular}

ing of rabbit platelets with ${ }^{35} \mathrm{SO}_{4}=$ was observed in this study with maximum labeling between 48 and $60 \mathrm{hr}$. It seems reasonable to assume that the labeled platelets appearing 2-3 days after the injection of the isotope are newly produced from the megakaryocytes and, therefore, represent young platelets.

The results of the present study show that when a population of platelets containing ${ }^{35} \mathrm{~S}-1 \mathrm{a}-$ beled young platelets is exposed to collagen, there is a fall in the specific radioactivity of the nonadherent platelets.

The ${ }^{35} \mathrm{~S}$-labeled platelets in the circulation $4-5$ days after the isotope injections are mainly those platelets released at 2-3 days which have survived $(3,4)$, and hence, represent an older platelet population. When a population of platelets containing these platelets is exposed to collagen there is no fall in the specific radioactivity of the platelets. Because at this time after a single injection

TABLE VIII

Platelet Radioactivity and Platelet Count before and after ADP Infusion

\begin{tabular}{|c|c|c|c|c|c|c|c|c|}
\hline \multirow[b]{4}{*}{ Experiment } & \multicolumn{8}{|c|}{ ADP infused $54 \mathrm{hr}$ after ${ }^{25 \mathrm{SO}_{4}-}$ administration } \\
\hline & \multicolumn{4}{|c|}{ Platelet radioactivity } & \multicolumn{4}{|c|}{ Plit $1 \mathrm{t} c)$ int } \\
\hline & \multirow[b]{2}{*}{ Preinfusion } & \multicolumn{3}{|c|}{ Postinf usion } & \multirow[b]{2}{*}{ Preinf usion } & \multicolumn{3}{|c|}{ Postinf usion } \\
\hline & & $1 \mathrm{~min}$ & $10 \mathrm{~min}$ & $90 \mathrm{~min}$ & & $1 \mathrm{~min}$ & $10 \mathrm{~min}$ & $90 \mathrm{~min}$ \\
\hline & \multicolumn{4}{|c|}{$\mathrm{cpm} / 10^{6}$ platelets } & \multicolumn{4}{|c|}{$\mathrm{No} . / \mathrm{mm}^{2} \times 10^{3}$} \\
\hline 1 & 42 & 52 & 39 & 44 & 252 & 101 & 216 & 215 \\
\hline 2 & 65 & 62 & 74 & 59 & 320 & 200 & 330 & 300 \\
\hline 3 & 14 & 15 & 15 & 15 & 361 & 216 & 311 & 350 \\
\hline
\end{tabular}


of ${ }^{35} \mathrm{SO}_{4}=$ the specific activity of the older platelets would not be very high, experiments were done in which an attempt was made to have considerable radioactivity in the older platelets. ${ }^{35} \mathrm{SO}_{4}=$ was administered for 7 days and platelets were prepared from blood drawn $72 \mathrm{hr}$ after the last injection. It is likely that a considerable portion of the ${ }^{35} \mathrm{~S}$ label was in the oldest platelets. Exposure of the platelet-rich plasma containing these platelets to collagen resulted in an increase in the specific radioactivity of the nonadherent platelets.

No evidence was found that these effects were related to the release of ${ }^{35} \mathrm{~S}$-labeled material from the platelets. In addition, when a young cohort of the platelet population was labeled with glycine${ }^{14} \mathrm{C}$, the results were similar to those obtained with ${ }^{35} \mathrm{~S}$-labeled platelets. Thus, the findings were not related to the type of isotope used or which constituents of the platelet were labeled. All this evidence is in agreement with the hypothesis that young platelets selectively adhere to collagen.

When $\mathrm{DF}^{32} \mathrm{P}$ was used as the platelet label, adherence of some of the platelets to collagen did not result in any change in the specific radioactivity of the platelets which were not adherent. This observation is in keeping with the concept that $\mathrm{DF}^{32} \mathrm{P}$ labels platelets of all ages equally.

In contrast to the adherence of platelets to collagen, we did not find that the adherence of ${ }^{35} \mathrm{~S}$ labeled platelets to each other, induced by ADP, was influenced by platelet age.

The results from the in vivo studies in which a collagen suspension was infused are consistent with the in vitro results. The specific radioactivity of the platelet population containing young labeled platelets fell, which indicated that young platelets were selectively removed from the circulation. This did not occur when the older platelets were labeled. In contrast to the effect of a collagen suspension, there appeared to be no difference between the effect of ADP on young and old platelets when this nucleotide was infused, although there was a large fall in the number of circulating platelets.

Wright (1) originally proposed that young platelets are more adhesive than older platelets. Although her studies were done with glass surfaces, the results from the present studies with collagen are in agreement with her findings. The ef- fect is related to the adherence of platelets to surfaces, not the adherence of platelets to each other.

Wright (1) suggested that the increase in sticky young platelets about the 10th postoperative day could be a factor in the increased incidence of thromboembolic disorders found after surgical operations. If exposure of subendothelial collagen is an initiating mechanism in thrombosis, our observations suggest that subjects with an increased proportion of young platelets might have a greater number of platelets adhere to collagen than normal subjects. It is possible that the increased platelet adhesiveness seen in association with thromboembolic disorders (12-15) may reflect a greater proportion of young platelets in the circulation of subjects with these conditions than in normal individuals.

\section{ACKNOWLEDGMENTS}

We wish to acknowledge the technical assistance of Mr. J. Schlamp, Mr. A. Senyi, and Mr. F. Skerlan in these experiments.

This paper was supported in part by grants from the Ontario Heart Foundation and Medical Research Council of Canada (MT 1309).

\section{REFERENCES}

1. Wright, H. P. 1942. Changes in the adhesiveness of blood platelets following parturition and surgical operations. J. Pathol. Bacteriol. 54: 461.

2. Hovig, T., L. Jørgensen, M. A. Packham, and J. F. Mustard. Platelet adherence to fibrin and collagen. J. Lab. Clin. Med. In press.

3. Odell, T. T., Jr., F. G. Tausche, and W. D. Gude. 1955. Uptake of radioactive sulfate by elements of the blood and the bone marrow of rats. Am. J. Physiol. 180: 491.

4. Robinson, G. A., A. M. Bier, and A. McCarter. 1961. Labelling of blood platelets of the pig with $\left({ }^{25} \mathrm{~S}\right)$ sulphate. Brit. J. Haematol. 7: 271.

5. Mustard, J. F., H. C. Rowsell, and E. A. Murphy. 1966. Platelet economy (platelet survival and turnover). Brit. J. Haematol. 12: 1.

6. Leeksma, C. H. W., and J. A. Cohen. 1956. Determination of the life span of human blood platelets using labelled diisopropylfluorophosphonate. J. Clin. Invest. 35: 964.

7. Murphy, E. A., and J. F. Mustard. 1961. Dicumarol therapy and platelet turnover. Circulation Res. 9: 402.

8. Hovig, T. 1963. Aggregation of rabbit blood platelets produced in vitro by saline "extract" of tendons. Thromb. Diath. Haemorrhag. 9: 248.

9. Packham, M. A., E. S. Warrior, M. F. Glynn, A. S. Senyi, and J. F. Mustard. 1967. Alteration of the response of platelets to surface stimuli by pyrazole compounds. J. Exptl. Med. 126: 171. 
10. Mustard, J. F., B. Hegardt, H. C. Rowsell, and R. L. MacMillan. 1964. The effect of adenosine nucleotides on platelet aggregation and clotting time. J. Lab. Clin. Med. 64: 548 .

11. Glynn, M. F., H. Z. Movat, E. A. Murphy, and J. F. Mustard. 1965. Study of platelet adhesiveness and aggregation with latex particles. J. Lab. Clin. Med. 65: 179.

12. McDonald, L., and M. Edgill. 1957. Coagulability of the blood in ischemic heart disease. Lancet. 2: 457.
13. Murphy, E. A., and J. F. Mustard. 1962. Coagulation tests and platelet economy in atherosclerotic and control subjects. Circulation. 25: 114.

14. Nestel, P. J. 1961. A note on platelet adhesiveness in ischaemic heart disease. J. Clin. Pathol. 14: 150.

15. Horlick, L. 1961. Platelet adhesiveness in normal persons and subjects with atherosclerosis. Effect of high fat meals and anticoagulants on the adhesive index. Am. J. Cardiol. 8: 459. 